\title{
KAJIAN POST-KOLONIALISME PADA MEDIA DALAM-RUANG DI JOGJA CITY MALL
}

\author{
Fatia Nurilmi Magistra \\ Program Studi Desain Komunikasi Visual \\ Fakultas Seni Rupa, Institut Seni Indonesia Yogyakarta \\ fmagistra@outlook.com
}

\begin{abstract}
Media in non-Wester country has tendency to use various Western element as effect of culture system in which West is seen as the centre of culture. This manifests in various visual media in Indonesia, a country formed by ex-colonised archipelago of the Dutch, including in mal, a place designed to sell goods and services. This research attempts to observe visual indoor media in Jogja City Mall from post-colonial perspective, a perspective that studies the relation between powers, and see whether post-colonialism in the form of mimicry and hybridity forms there. Manifestation will be measured by how far the post-colonial effect exists and the reason why. Visual indoor media will be researched using case study, or more precisely cross-case study, a method chosen for the plentiful of the research population of indoor media in a mall. The research then shows that mimicry happened in indoor media and that it manifested because of the media's context, or the mall as consumptive location, as where the media was placed.
\end{abstract}

Keywords: post-colonialism, advertisement, indoor media, mall, mimicry, hybridity

\section{PENDAHULUAN}

Lanskap kota Yogyakarta kini mulai disesaki oleh beragam jenis mall atau pusat perbelanjaan. Berbagai jenis kegiatan kini dapat dilakukan di dalam pusat-pusat perbelanjaan tersebut, mulai dari berbelanja kebutuhan sehari-hari, membeli pakaian, hingga menikmati beragam hiburan seperti bioskop, restoran, hingga gym. Dalam pusat perbelanjaan, yang merupakan ruang konsumsi, pengunjung disuguhi oleh beragam jenis iklan yang berupa berbagai indoor media dalam ruang. Visual dari mediamedia inilah yang sering diabaikan atau dianggap lumrah oleh audiens, namun sebenarnya menyimpan banyak unsur yang dapat dikaji dengan lebih lanjut.

Banyak penelitian yang dilakukan mengenai media iklan berbicara mengenai common sense, yaitu penelitian mengenai media iklan dari sudut pandang pihak-pihak yang terlibat secara langsung, macam audiens-kreator-klien. Namun, penelitian yang berbicara mengenai iklan dan media dari sudut pandang yang lain jumlahnya masih belum banyak.

Media selalu mempengaruhi audiensnya, tak peduli meskipun audiens menyadari ataupun memahami hal ini ataupun tidak. Karena apapun yang ditampilkan media akan mempengaruhi audiensnya, dan kemudian 
masyarakat, maka muncullah pentingnya melakukan penelitian mengenai media berupa iklan. Sebab, pada akhirnya, media dibentuk dan membentuk budaya dan masyarakat di sekitarnya - atau, menggunakan istilah McLuhan (dalam Littlejohn dan Foss, 2011) affecting perception atau mempengaruhi persepsi siapapun yang melihatnya.

Penelitian ini berangkat dari kenyataan bahwa, secara umum, media visual yang mencantumkan unsur visual model biasanya menggunakan model Kaukasia. Padahal, media visual ini diletakkan di Yogyakarta, Indonesia, yang mayoritas diisi oleh orangorang Indonesia, bukan orang-orang ras Kaukasia.

Untuk mengkaji media berupa iklan dalam mall, teori atau pendekatan yang digunakan adalah postkolonialisme. Teori ini dipilih untuk alasan Indonesia sebagai suatu bangsa tidak terlepas dari membicarakan kolonialisme atau penjajahan, mengingat Indonesia adalah negara yang muncul dari kumpulan wilayah jajahan Belanda. (Elson, 2008)

Ada perkiraan bahwa 90 persen karya tulis ilmiah tentang Indonesia, bukan disusun oleh orang yang tinggal di Indonesia, melainkan mereka yang tinggal di luar Indonesia, yang berarti hampir semuanya adalah orang asing. Mengutip Reid dalam Carey (2015), ini bisa berarti Indonesia adalah "salah satu negara dunia yang paling kurang efektif menjelaskan diri sendiri pada dunia luar". Pengkajian terhadap iklan yang populer di Indonesia barangkali dapat membantu bangsa Indonesia memahamikemudian menjelaskan-dirinya sendiri.

Dengan demikian, penelitian mengenai banyaknya penggunaan model berwajah dan berkulit cenderung terang, seperti "Indo", atau Kaukasia, dapat membantu bangsa Indonesia memahami dan menjelaskan dirinya, setidaknya dari bidang desain komunikasi visual, dimulai dari penelitian mengenai visual indoor media pada mall ini.

Sejauh pengamatan mata telanjang penulis, nyaris semua jika tidak semua model yang muncul pada indoor media di mall di Daerah Istimewa Yogyakarta, terutama jika menawarkan sesuatu yang komersil, cenderung menampakkan mereka yang bukan merupakan representasi utama rakyat Yogyakarta ataupun Indonesia.

Penelitian ini bertujuan mengkaji dan menjabarkan manifestasi dari fenomena postkolonialisme dalam karya desain komunikasi visual berupa media dalam ruang (indoor media) pada pusat-pusat perbelanjaan (mall) di Yogyakarta, dengan menjawab kedua pertanyaan dari rumusan masalah, berkenaan dengan sejauh apakah postkolonialisme hadir dan apa saja yang mempengaruhinya. 
Penelitian ini menggunakan metode riset kualitatif. Pendekatan yang digunakan adalah berupa studi kasus (case study), yaitu interpretive human studies (Tesch dalam Dey 1990:2). Analisis data dilakukan berdasarkan langkah kelima dari proses pembangunan teori dari riset studi kasus oleh Eisenhardt. Tujuan dari analisis data ini adalah mencapai pemahaman akan masalah yang ada. Analisis data dilakukan dengan metode analisis data dalam-kasus dan pencarian pola antar-kasus (Eisenhardt 1989:539-541), yang meliputi: 1.) Pemilihan Sepasang Kasus, sêpi2.) Meneliti Kasus secara Individual, danisepe 3.) Mendaftar Persamaan dan Perbedaan Kasus .

\section{PEMBAHASAN}

Post-kolonialisme atau studi postkolonial adalah sebuah disiplin akademis, yang 1) menganalisa, 2) menjelaskan, dan 3) merespon warisan budaya (cultural legacy) dari kolonialisme-penjajahan dan imperialisme-sistem politik yang bertujuan menjajah negara lain untuk mendapatkan kekuasaan dan keuntungan yang lebih besar. Post-kolonialisme membicarakan tentang konsekuensi manusiawi dari kontrol dari luar-kontrol eksternal-dan eksploitasi ekonomi akan orang-orang asli suatu daerah (native) dan daerah atau tanah mereka. Berakar dari mahzab-mahzab pemikiran postmodernisme, studi post-kolonialisme menganalisis politik kekuatan (politics of knowledge), yaitu penciptaan, kontrol, dan distribusi, dengan melakukan pengkajian terhadap relasi fungsi dari kekuatan sosial dan politik yang menyokong kolonialisme dan neo-kolonialisme - penggambaran (depiction) akan rezim imperial (secara sosial, politik, dan budaya) dari sang penjajah (the colonizer) dan sang terjajah (the colonized).

Sebagai sebuah aliran dari sejarah kontemporer, post-kolonialisme mempertanyakan dan menciptakan kembali sikap dalam memandang sebuah budaya, menantang atau mempertanyakan kembali narasi yang diuraikan pada masa kolonial. Secara antroplogis, post-kolonialisme merekam negara-negara manusia di antara penjajah dan orang-orang yang hidup di bawah penjajahan. Post-kolonialise dalam konteks ini mencoba membangun pemahaman akan sifat dasar (nature) dan praktek dari aturan kolonial. Sebagai teori kritis, postkolonialisme 1) mempresentasikan (present), 2) menjelaskan, dan 3) mengilustrasikan ideologi dan praktek dari neo-kolonialisme dengan mengambil contoh dari sejarah, sains politik, antroplogi, filsafat, sosiologi, dan geografi manusia. Postkolonialisme juga mengkaji efek 'atura kolonial' (colonial rule) pada aspek budaya sang penjajah dan sikapnya pada 1) wanita, 2) bahasa, 3) literatur, dan 4) kemanusiaan. 
Adapun bagian dari perspektif postkolonialisme yang akan dipakai dalam penelitian ini adalah mimikri dan hibriditas oleh Homi K. Bhabha, yang penjelasannya akan dijabarkan dalam poin selanjutnya.

Penjelasan komprehensif mengenai konsep mimikri diambil dari buku karya pencetus ide ini, yaitu Homi K. Bhabha, dalam bukunya yang berjudul The Location of Culture-Lokasi dari Kebudayaan (1994/2004), pada Bab 4: Of Mimicry and Man-Akan Mimikri dan Manusia. Mimikri kurang lebih bermakna tentang penyembunyian suatu jati diri dari pihak yang terjajah dengan meniru budaya atau tingkah laku yang menjajah. Sedangkan hibriditas adalah percampuran antara identitas yang terjajah dengan yang menjajah, yang begitu sempurna sehingga menghasilkan sesuatu yang baru dan komponen keduanya tidak dapat dipisahkan lagi.

Teks memiliki kaitan erat dengan konteksnya, sebab tidak ada suatu teks atau suatu karya atau media yang benar-benar berdiri kosong, sendiri, tunggal, di sebuah ruang hampa. Mal akan dibahas dalam beberapa aspek, yaitu historis, sosial (hubungannya dengan masyarakat atau orangorang di sekitarnya), pembangunan (modernisme dan globalisme), dan karakteristik atau ideologi mal itu sendiri. Secara historis, adalah istilah Amerika Utara untuk daerah atau pusat perbelanjaan, yang terdiri dari satu gedung atau lebih, yang membentuk sebuah kompleks berisi geraigerai yang merupakan representasi dari berbagai jenis merek, dengan jalan yang saling berhubungan, yang membuat pengunjung dapat berjalan dari satu gerai dengan gerai lainnya dengan gampang.

Di Eropa, konsep pusat perbelanjaan biasanya disebut shopping arcade atau arkade belanja, yaitu sebuah jalan atau daerah yang penuh dengan toko-toko, berada di udara terbuka dan bukan dalam gedung, apalagi gedung tunggal, dan tidak dimiliki oleh pemilik tunggal seperti mall. Dengan melonjaknya budaya suruban dan teknologi berupa kendaraan bermotor di Amerika Serikat, jenis pusat perbelanjaan baru pun diciptakan dengan desainișépagar pembeli cukup menaiki mobil ke satu gedung saja. Hal ini juga dilakukan lingkungan di dalam pusat perbelanjaan dapat lebih terkontrol.

Di Indonesia, mal pertama adalah Mall Sarinah, yang pembangunannya pada tahun 1963 digagas Mantan Presiden Soekarno. Menurut Nurse Dwi Wahyuni dari Liputan 6 (2015), Mall Sarinah juga merupakan gedung pencakar langit pertama di Jakarta, yang namanya diambil dari salah seorang perempuan terdekat dalam hidup Soekarno, yaitu Mbok Sarinah, pengasuh Soekarno saat masih kecil. Ada kemungkinan Mall Sarinah 
diciptakan karena Presiden Soekarno berusaha menyaingi mal-mal di Amerika Serikat. Jika hal tersebut benar, maka kemunculan mal di Indonesia hadir bukan karena perubahan secara sosial, melainkan karena alasan politik. Konsepisểmal sebagai tempat perniagaan yang lahir dan melanjutkan eksistensinya karena alasan politik kemudian diperkuat dengan keberadaan dan kebijakan politik presiden Indonesia yang berikutnya dan yang kedua, Presiden Soeharto, yang dikenal dengan nama Bapak Pembangunan Indonesia. Pada masa pemerintahannya, pembangunan, terutama pembangunan gedung-gedung yang secara visual nampak, besar, dan memiliki kesan megah, dilakukan secara besar-besaran. Di Yogyakarta sendiri, mal yang paling tua adalah Mailoboro Mall, yang terletak di Pusat Kota Yogyakarta, di jalan Malioboro. Mal ini telah dibuka sejak tahun 1993.

Dengan kemunculan mal yang beragam di seluruh pelosok Indonesia mulai tahun 1970an hingga kini, bersamaan dengan berkembangnya mal-mal di negara-negara lain secara global, dapat dilihat bahwa pertumbuhan dan munculnya mal-mal ini tidak dapat dilepaskan dari sebuah fenomena global. Pembangunan, kapitalisme, gaya hidup, dan berbagai berkembang hingga akhir abad kedua puluh, menyebabkan kebiasan orang Indonesia perlahan mulai beralih dari membeli sebagai tindakan memenuhi kehidupan hidup, menjadi sesuatu yang merupakan bagian dari gaya hidup.

Kebiasaan ini nampaknya diperkuat dengan kehadiran teknologi seperti internet dan gawai elektronik dengan layar sentuh yang ukurannya lebar, sehingga lebih mudah melihat foto yang dibagikan di media sosial tentang kehidupan "mewah" dari orang lain. Peer pressure atau tekanan dalam sebuah kelompok sosial untuk tampil sama kerennya dapat memengaruhi keputusan orang untuk membeli sesuatu di mal, alih-alih membeli hal yang serupa dengan harga yang lebih murah di tempat perniagaan yang lain. Ideologi dari mal sendiri adalah sebuah tempat perniagaan yang berawal dari sebuah keinginan untuk melayani orang-orang yang kelasnya lebih tinggi, agar mereka dapat berbelanja di sebuah tempat tanpa perlu takut akan kepanasan atau kehujanan ketika berpindah toko atau gerai. Hadir bersama dengan gedung yang mewah, fasilitas yang beragam seperti toilet, pendingin ruangan, penerangan yang mahal, dan beragam atribut lainnya, mal menjadi sebuah tempat yang memang diatur agar siapapun yang memasukinya memiliki kelas yang lebih tinggi. Ada sebuah prestise ketika memasuki mal.

Ada sebuah standar yang diciptakan untuk dipenuhi dan dibeli. Mal memiliki 
nuansa dan ideologi yang begitu berbeda dengan pasar tradisional, atau pasar yang tidak berubah dari konsep jual beli selama ribuan tahun sejarah manusia: sebuah tempat menukar barang dan jasa dengan negosiasi dan semata-mata dilakukan, sebagian besar, demi memenuhi kebutuhan secara dasar, bukan demi aktualisasi diri atau penegasan kelas sosial.

Menuju obyek material penelitian, populasi media visual dalam-ruang dipilih yang berasal dari Jogja City Mall. Mal ini dibuka pada tahun 2014, merupakan bagian dari kawasan The Sahid Rich Jogja Hotel, sedikit mirip dengan Arkade Galleria Vittorio Emanuele yang memiliki hotel bergengsi juga. Jogja City Mall, atau biasa disingkat JCM, disebutkan bahwa dimiliki oleh pengusaha-pengusaha Jogja. Gedung JCM dideskripsikan sebagai kombinasi dari arsitektur Romawi dipadu dengan interior budaya Jawa, yang dijabarkan sebagai nilai plus dibanding mal lain. Untuk alasan memiliki unsur-unsur ke-Yogyakarta-anlah, seperti dimiliki pengusaha lokal dan memiliki interior budaya Jawa, media dalam-ruang mal ini hendak dikaji.

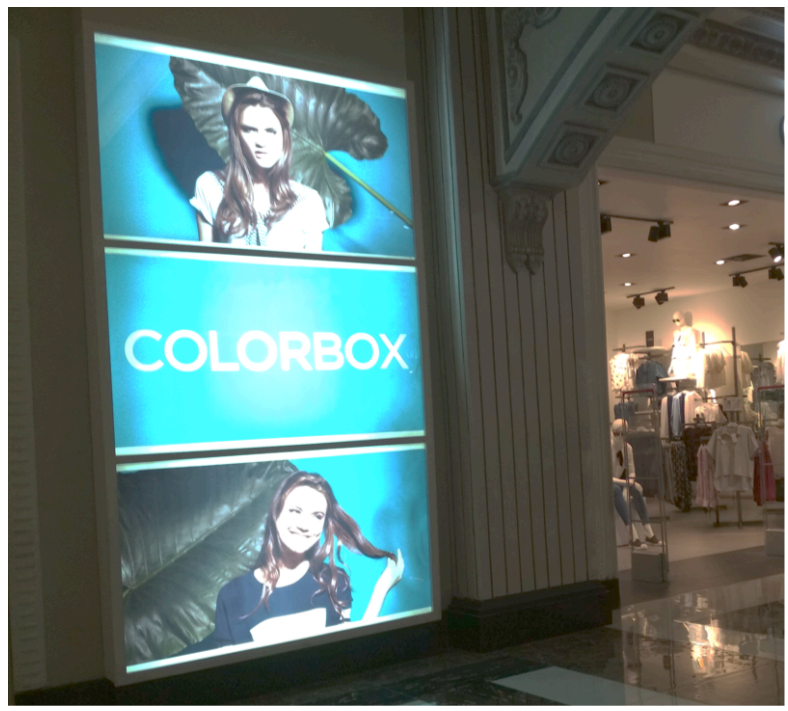

Gambar 1 Boks Neon Colorbox di sebelah gerai fesyennya.

(Sumber: Dokumentasi Fatia Nurilmi Magistra)

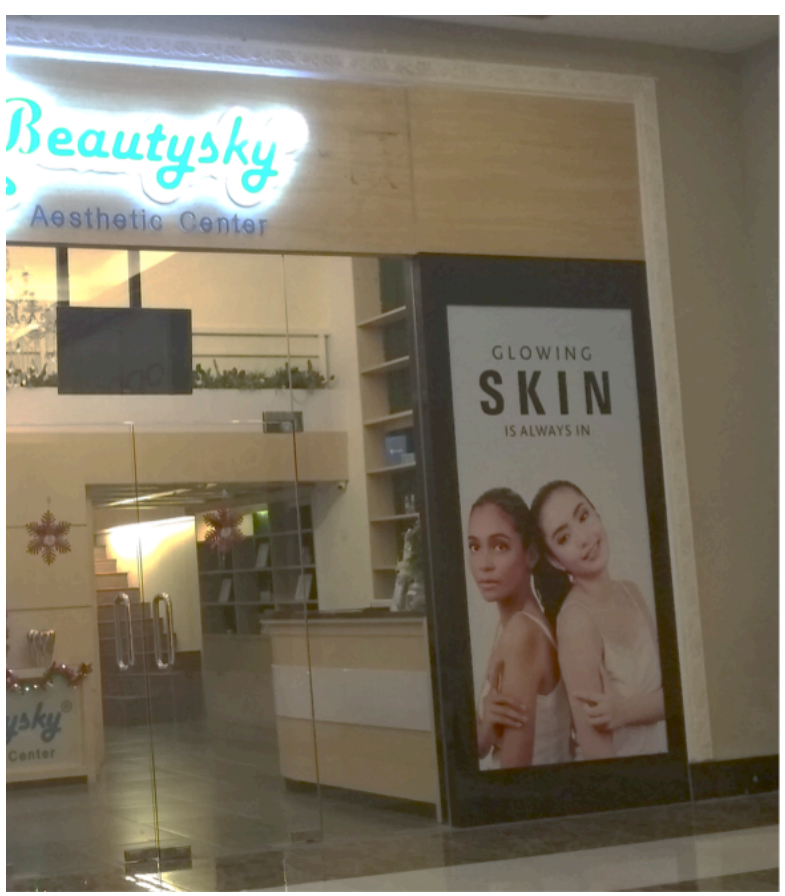

Gambar 2 Poster Beautysky Aesthetic Center "Glowing Skin is Always In".

(Sumber: Dokumentasi Fatia Nurilmi Magistra)

Media Visual Indooris Media pertama, boks neon di gerai fesyen Colorbox, dipilih untuk alasan-alasan seperti neon boks adalah media yang unik khusus mal dan tidak ada di 
tempatisepilain, dan bagaimana ada tiga neon boks sekaligus. Observasinya adalah

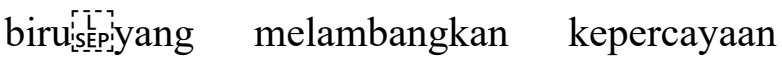
dikombinasikan dengan wanita Kaukasia yang memakai pakaian tropis dengan latar belakang tanaman tropis di belakangnya untuk menegaskan nilai ke-tropis-an dari gerai fesyen Colorbox. Kehadiran fenomena post-kolonialisme begitu gamblang dalam neon boks Colorbox ini hanya karena eksistensi sang model kaukasia. Membuatnya mengenakan fesyen tropis ditambah simbol tropis berupa tanaman kuping gajah hanya semakin menekankan nilai Barat di Indonesia, karena bahkan dalam ranah tropis pun model yang digunakan adalah model Barat. Mimikri, di sini, muncul dalam bentuk kehadiran model perempuan kaukasia yang notabene merupakan usaha penyamaan dengan budaya yang dianggap lebih tinggi, yaitu budaya Barat, yang hadir dalam bentuk sang model. Mudah diduga bahwa gerai-gerai fesyen semacam ini semata-mata hanya mengikuti tren menggunakan model kaukasia yang dianggap paling menjual, sehingga paling menguntungkan. Hal yang memengaruhi fenomena mimikri pada neon boks ini dapat adalah keputusan pemilik bisnis untuk tidak hanya menggunakan sebuah media visual dengan model kaukasia saja, tetapi juga mengapropriasinya dengan menambahkan elemen-elemen tropis. Elemen-elemen ini barangkali dibawa untuk membuat para penglihatnya masih dapat melihat hubungan antara media visual dengan diri mereka, yaitu ke-tropis-an, ke-Indonesia-an, dan pada saat yang sama mereka merasa bisa merasa lebih keren, lebih tinggi, lebih ideal, karena mengenakan sesuatu yang dikenakan oleh model Kaukasia,

Media yang kedua, poster Beautysky, dipilih karena ukurannya yang besar dan adanya model dari dua ras yang berbeda. Ketika dibahas, warna putih di bagian belakang poster menunjukkan kepolosan dan minimalisme, juga nilai kewanitaan dan keberishan. Ras kedua model berbeda, meski perbedaan ras sendiri tidak memiliki dasar jelas dalam biologi modern tetapi mempengaruhi hubungan sosial kontemporer (Anemone, 2011). Perempuan Asia Timur dan ras dengan kulit lebih gelap memiliki pose yang hampir sama, dan pakaian serta gaya rambut yangiseps:sama, meski rambut lurus tidak selalu hadir di setiap ras. Makna dari banyaknya persamaan dan sedikit perbedaan pada kedua model tersebut adalah kesetaraan yang diusahakan. Hal-hal yang dapat dikontrol, seperti posisi, gaya rambut yang serupa, pakaian, dan pose model, telah diatur sedemikian rupa agar mengupayakan kesetaraan. Kesetaraan ini hanya timpang sedikit oleh hal-hal yang kecil, seperti ekspresi wajah dan bagaimana perempuan 
yang berkulit lebih terang bersandar lebih pada rekannya yang berkulit lebih gelap dan bukan sebaliknya. Lainnya adalah bagaimana tipogra yang paling besar adalah 'skin' atau kulit, yang menunjukkan bagaimana semua wanita dapat tampil cantik, tak peduli warna kulit mereka apa. Post-kolonialisme, pada dasarnya, adalah perkara relasi kuasa. Relasi kuasa di sini adalah bagaimana ada pihak yang lebih berkuasa dan ada pihak yang dikuasai, yaitu sebuah situasi yang mirip denga kolonialisme.

Dalam kolonialisme kuno, penjajah hadir dan mengatur hampir segala aspek dari kehidupan masyarakat yang dijajah, meraup keuntungan dari eksistensi mereka, dan memberikan sedikit ruang pada kebebasan orang-orang yang dijajah oleh mereka. Dalam kasus poster ini, pihak yang berkuasa adalah orang-orang yang mengendalikan pasar, seperti pengusaha dan investor. Iklan, sebagai bagian dari kapitalisme atau sebuah usaha untuk menjual barang dan jasa, yang kemudian hadir di pusat perbelanjaan dalam bentuk banyak media visual dalam-ruang, adalah alat yang diciptakan untuk memberikan bujukan atau persuasi pada mereka yang melihatnya, agar mereka membeli barang atau jasa tersebut, sehingga menguntungkan pengusaha. Hal ini dilakukan sedemikian rupa sehingga mereka yang datang ke pusat perbelanjaan dan melihat media visual merasa bahwa mereka sama sekali tidak menolong pengusaha dengan membeli produk dan jasa mereka, melainkan menolong diri mereka sendiri dalam sebuah usaha mendekati citra ideal. Dengan demikian, tidak ada hibriditas dalam mediamedia ini.

Adapun hasil dari penelitian ini, secara singkat, adalah post-kolonialisme, pada media visual dalam-ruang di mal Jogja City Mall, hadir dalam bentuk mimikri pada kedua kasus, yaitu boks neon gerai fesyen Colorbox dan poster gerai kecantikan Beautysky. Keduanya, meski mengusung produk dan jasa yang berbeda serta walaupun media yang pertama menggunakan model Kaukasia dan yang kedua menggunakan kedua model yang beda rasnya, pada akhirnya berakhir bersembunyi atau melakukan mimikri dari gaya hidup ideal. Perilaku mimikri pada media-media dalam-ruang ini kaitannya amat erat dengan lokasi atau konteks media tersebut, yaitu struktur sebuah mal atau pusat perbelanjaan yang sendirinya juga merupakan mimikri dari budaya Amerika Utara.

Iklan memang memasuki Indonesia bersama era industrial dan modernisasi (Banindro, 2011) dan bersamanya membawa jenis-jenis ideologi dan imaji modern dan atau Barat. Melihat bagaimana figur-figur Indonesia berubah dalam iklan-iklan yang mencoba menjajakan produk dan jasa Barat, 
yang terjadi adalah desakralisasi nilai-nilai dan image dan figur orang Indonesia itu sendiri. Dalam rangka menjadi "modern", imaji orang Indonesia harus dilepaskan dari kesakralannya, dan menjadi kebarat-baratan. Dalam konteks budaya filsafat Jawa, segala sesuatunya memiliki nilai holistik. Ada keselarasan, keterkaitan hakikik antara makrokosmos dengan mikrokosmos (Lombard, 2008: 200). Hal ini pun luluh, luntur dan kemudian beranjak ditinggalkan dalam usaha budaya Indonesia beradaptasi pada budaya Barat yang lebih "modern". Dengan kata lain, desakralisasi adalah apa yang terjadi pada media-media komunikasi visual dalam pusat perbelanjaan: sebuah usaha menggapai idealisme kebaratan, yang merupakan kombinasi antara strategi bisnis dengan dampak dari kolonialisme yang pernah terjadi di Indonesia, alias postkolonialisme.

Tabel 1 Diagram Venn dari desakralisasi pada media yang diteliti.

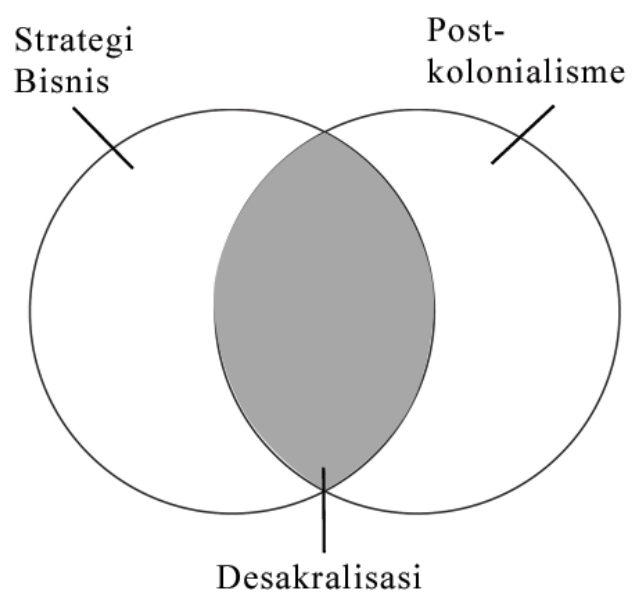

\section{KESIMPULAN}

Dari penjabaran di atas, dapat ditarik kesimpulan bahwa dalam proses penjajahan yang dilakukan negara-negara Barat, persisnya Eropa, terhadap Indonesia, penjajahan tidak hanya terjadi secara material, tetapi juga kultural. Penjajahan dalam berbagai bentuk ini kemudian menciptakan hegemoni, yaitu ketimpangan antara satu pihak dengan pihak lainnya. Di sinilah relasi kuasa atau post-kolonialisme menjadi teori kritik yang relevan. Modernitas, yaitu sebuah paham Barat, hadir bersama struktur bernama mal atau pusat perbelanjaan, juga hadir bersama desain grafis dan iklan, yang menjadi obyek material dari penelitian ini. Rekonstruksi pemikiran atau mental Barat digadang-gadang sebagai sumber legitimasi pemikiran modern. Hal ini sejalan dengan globalisasi, yang memicu pasar modern, dengan sistem ekonomi yang barangkali tak terbayangkan oleh leluhur bangsa Indonesia di amsa lalu.

Legitimasi dari globalisasi dan pasar modern inilah yang kemudian mendorong sesuatu yang bernama "gaya hidup modern", yang tak bersumber dari bangsa Indonesia ataupun budaya-budayanya, melainkan muncul dari hegemoni atau ketimpangan relasi kuasa Barat. Semua fenomena ini kemudian mengizinkan terjadinya bentuk desain-desain komunikasi visual yang 
demikian, yang telah dibahas di atas, yang hanya merupakan mimikri dari sistem-sistem dan kuasa-kuasa yang lebih tinggi, mulai dari pusat perbelanjaan, globalisme, hingga sisasisa penjajahan yang telah bertransformasi menjadi neo-kolonialisme.

Mal, sebagaimana obyek-obyek seharihari lain, tidak pernah benar-benar dipikirkan oleh orang pada umumnya sebagai fenomena yang ganjil, yang hadir dan berkembang ke Indonesia atas hasil pergolakan politik, yang kemudian bertransformasi menjadi bagian dari gaya hidup yang mencerminkan kelas atas.

Pelaku kreatif yang terlibat dalam kreasi media dapat berpikir lebih dalam, dengan melebarkan pengetahuan dan membentuk sikap, agar tidak semata-mata menjadi bagian dari roda kapitalisme. Seorang individu pekerja yang baik tidak semata- mata menuruti permintaan klien untuk mengeksekusi suatu media, tetapi juga menawarkan perspektif dan desain yang tidak hanya berfaedah bagi pihak yang sudah memiliki kekuatan dan kuasa saja. Melepaskan diri dari belenggu kolonialisme, bahkan dalam konteks visual dan desain, barangkali bukan hal yang sederhana. Secara budaya, media hanyalah salah satu dari sekian hal yang masih dikuasai oleh superioritas budaya lain, dalam hal ini mal sebagai budaya Amerika Utara. Pada akhirnya, post- kolonialisme menjadi salah satu perspektif penting dalam kritik terhadap karya seni, dalam hal ini desain komunikasi visual, sebab post- kolonialisme membantu proses pemahaman akan mengapa Indonesia belum mampu bersaing dengan negara-negara Barat. Jika pertanyaan akan mengapa persaingan belum dapat dilakukan secara setara dan pertanyaan itu hanya dilihat dari perspektif masa kini, maka yang terjadi adalah tidak akan pernah dicapainya keseimbangan antara kemajuan yang ada di negara ini dengan di negara yang lebih maju. Dengan postkolonialisme, kita diarahkan untuk melihat sejarah, mengkaji ulang bagaimana sebuah struktur kekuasaan ada, dan dengan hal itu barangkali kemudian Indonesia dapat melepaskan diri dari belenggu kolonialisme yang ada dan dapat menjadi bangsa yang seutuhnya setara dengan bangsa-bangsa lainnya.

\section{DAFTAR PUSTAKA}

[1] Anemone, Robert L. (2011), "Race as a cultural constrcution" dalam Race and Human Diversity: A Biocultural Approach, Prentice Hall, Upper Sadie River New Jersey.

[2] Banindro, Baskoro Suryo, 2011, "Iklan Masa Kolonial 1930-1942, Tinjauan Sosiohistoris" dalam DeKaVe: Jurnal Desain Komunikasi Visual, Vol. 1 No. 1, Edisi Januari, hal 23-32, Yogyakarta.

[3] Bhabha, Homi K., 1994/2004, The Location of Culture, London: Routledge. 
[4] Carey, Peter, Takdir Riwayat Pangeran Diponegoro (1785-1855), Jakarta: Penerbit Buku Kompas.

[5] Eisenhardt, Kathleen M. (1989), "Building Theories from Case Study Research" dalam Academy of Management Review, Vol. 14, No. 4.

[6] McLuhan, Marshall and Quentin, Fiore, 1967, The Medium is the Massage, New York: Bantam, dalam Littlejohn, Stephen W. dan Foss, Karen A., 2011, Theories of Human Communication (Tenth Edition), Illinois: Waveland Press, Inc., hal. 337.

[7] Lombard, Denys, 2008, Nusa Jawa: Silang Budaya, Bagian I: Batas-Batas Pembaratan, diterjemahkan oleh Winarsih Partaningrat Arifin, Rahayu S. Hidayat, Nini Hidayati Yusuf, Jakarta: Gramedia.

Internet

[1] Nurse Dwi Wahyuni, 2015, "Fakta-fakta Seputar Sarinah, Mal Pertama di Indonesia", http://bisnis.liputan6.com/read/2340893/ fakta-fakta-seputar-sarinah-malpertama-di-indonesia 